\title{
SAW THICKNESS IMPACT ON COTTON GIN ENERGY CONSUMPTION
}

\author{
Paul A. Funk ${ }^{1, *}$, Joseph W. Thomas², Kathleen M. Yeater ${ }^{3}$, Carlos B. Armijo ${ }^{1}$, \\ Derek P. Whitelock ${ }^{1}$, John D. Wanjura ${ }^{4}$, Christopher D. Delhom ${ }^{2}$ \\ ${ }^{1}$ USDA ARS Southwestern Cotton Ginning Research Lab, Las Cruces, New Mexico, United States. \\ ${ }^{2}$ USDA ARS United States Cotton Ginning Research Unit, Stoneville, Mississippi, United States. \\ ${ }^{3}$ USDA ARS Plains Area, Ft. Collins, Colorado, United States. \\ ${ }^{4}$ USDA ARS Cotton Production and Processing Research Unit, Lubbock, Texas, United States. \\ *Correspondence: paul.funk@usda.gov
}

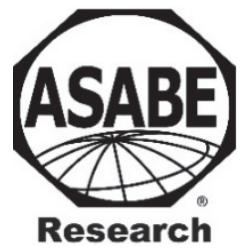

\section{Highlights}

- Cotton gin saws 0.91 and $1.14 \mathrm{~mm}$ thick were compared.

- Thicker saws had approximately $10 \%$ lower processing rate at full motor load.

- Thicker saws used about $35 \%$ more energy to gin the same amount of lint.

\begin{abstract}
Most cotton fiber (lint) is separated from the seed by gin saw teeth that pull the lint between metal bars (ribs). These ribs are spaced close enough to each other that the seeds cannot pass with the lint. Cotton gin saws are available in three thicknesses, 0.9144, 0.9398, and $1.143 \mathrm{~mm}(0.036,0.037$, and $0.045 \mathrm{in}$.). No data from controlled experiments has been published which compares the effect of saw thickness on the economically important performance measures gin processing rate and energy consumption. Two shafts were prepared by installing, at the proper spacing, $406 \mathrm{~mm}$ (16 in.) diameter saws of 0.9144 and $1.143 \mathrm{~mm}$ thickness for testing on a reduced-width (46-saw) Continental Double Eagle gin stand with constant rib spacing at the USDA-ARS Southwestern Cotton Ginning Research Laboratory in Las Cruces, New Mexico. Energy consumption was recorded for target processing rates 4.88 and $6.08 \mathrm{~g} \mathrm{saw}^{-1} \mathrm{~s}^{-1}$ using pre-cleaned seed cotton grown in New Mexico, Texas, and Mississippi in a randomized complete block experiment with five replicates. On this equipment we found that the thicker saws averaged $90 \%\left(4.69 \mathrm{~g} \mathrm{saw}^{-1} \mathrm{~s}^{-1}\right)$ the processing rate of the thinner saws $\left(5.21 \mathrm{~g} \mathrm{saw}^{-1} \mathrm{~s}^{-1}\right) . \mathrm{Net}^{-1}$ ginning energy of the $1.143 \mathrm{~mm}$ gin saws was $26.5 \mathrm{~W}-\mathrm{h} \mathrm{kg}^{-1}$ compared to $19.7 \mathrm{~W}$-h $\mathrm{kg}^{-1}$ for the $0.914 \mathrm{~mm}$ saws, or about $35 \%$ more energy. Results were consistent for cottons from all three regions. Thicker saws are less likely to break under harsh conditions at the ends of the gin stand and are still recommend for use there, but there appears to be no advantage with regard to processing rate or energy use to installing thicker saws across the full width of the gin stand if rib spacing remains unchanged.
\end{abstract}

Keywords. Cotton gin, Energy use, Gin saw thickness, Processing rate.

$\mathrm{T}$ he main function of the cotton gin is to remove fiber (lint) from the cotton seed. For approximately $95 \%$ of U.S. cotton this is accomplished in a saw gin. The teeth of rotating gin saws grasp the lint and pull it through ginning ribs (fig. 1). The gap between the ribs is too narrow for the seed to pass, resulting in separation (Anthony and Mayfield, 1994).

\footnotetext{
cc) $\$($ The authors have paid for open access for this article. This NonCommercial-NoDerivatives 4.0 International License https://creative commons.org/licenses/by-nc-nd/4.0/.

Submitted for review on 12 March 2021 as manuscript number MS 14535; approved for publication as a Research Article by the Machinery Systems Community of ASABE on 13 December 2021.

This research was supported by the U.S. Department of Agriculture, Agricultural Research Service. Mention of trade names or commercial products in this publication is solely for the purpose of providing specific information and does not imply recommendation or endorsement by the U.S. Department of Agriculture. USDA is an equal opportunity provider and employer.
}

Historically, cotton gin saws have been produced in three thicknesses, 0.9144, 0.9398, and $1.143 \mathrm{~mm}(0.036,0.037$, and 0.045 in.), depending on the manufacturer. Some ginners (cotton gin facility owners/operators) modify their gin saw cylinder to address the following problem: There is less seed cotton supplied from the extremities of a typical gin stand feeder because of edge effects. This results in less seed cotton at the extremities of the saw gin stand seed roll, which causes cottonseed to migrate to the edges, increasing seed roll density near each end of the roll box; This increases the risk of saw damage there. Cotton gin profitability has a positive correlation with processing rate, which is maximized when down time is minimized (Funk and Hardin IV, 2017). To reduce potential down time, thicker gin saws have been used in the two positions at each end of a saw cylinder where saw breakage most often occurs (conferring durability to the location most responsible for down time, while maintaining economy across the rest of the cylinder). 
Antecedent research has identified ginning energy consumption for commercial facilities in the United States both at one moment in time with audits (Funk and Hardin IV, 2012); Funk et al. (2013) and throughout the season with monitoring studies (Hardin IV and Funk, 2012). Published values for gross energy consumed by the gin stand averaged 27.3 and $26.0 \mathrm{~W}-\mathrm{h} \mathrm{kg}^{-1}$ for the audits and monitoring studies, respectively. Energy consumption at idle was not recorded during the audits. For the four monitored facilities, subtracting the energy used at idle resulted in an estimate of the energy used exclusively for seed-fiber separation, which averaged $20.6 \mathrm{~W}-\mathrm{h} \mathrm{kg}^{-1}$. The monitored facilities were located in each of the four cotton production regions in the United States (Southeast, Mid-south, Southwest, and West).

Another estimate of energy used exclusively for seed-fiber separation was obtained by Boykin (2007), who subtracted the energy used at idle to measure the gin saw energy for 65 different Mississippi cultivars, finding that the variation in energy consumption was due to differences in fiberseed bond strength. He reported an average of $20.2 \mathrm{~W}-\mathrm{h} \mathrm{kg}$ ${ }^{1}$ lint ginned, with a range of 16.4 to $24.3 \mathrm{~W}-\mathrm{h} \mathrm{kg}^{-1}$ on a Continental 93 (reduced to 20 saws) gin stand at the USDA-ARS Ginning Laboratory in Stoneville, Mississippi. Note the similarity between commercial gin results and those of Boykin's 2007 lab test.

Additionally, Boykin (2007) reported that ginning energy was found to correlate with changes in seed linters content, ginning rate, seed percent, and turnout, but ginning energy did not appear to be dependent on these factors. Gin stand energy decreased for cultivars with large seed and low seed linters content. Ginning energy did not change with fiber length, but it increased with short fiber content as more fibers were broken in multiple places. Cultivars that used less energy during ginning tended to have higher HVI fiber strength, so reduced fiber-seed bond strength was not the result of reduced fiber strength. Ginning energy increased with the number of neps, number of seed coat neps, and weight of seed coat fragments, and decreased with seed cotton cleaner efficiency indicating that it took additional energy to remove

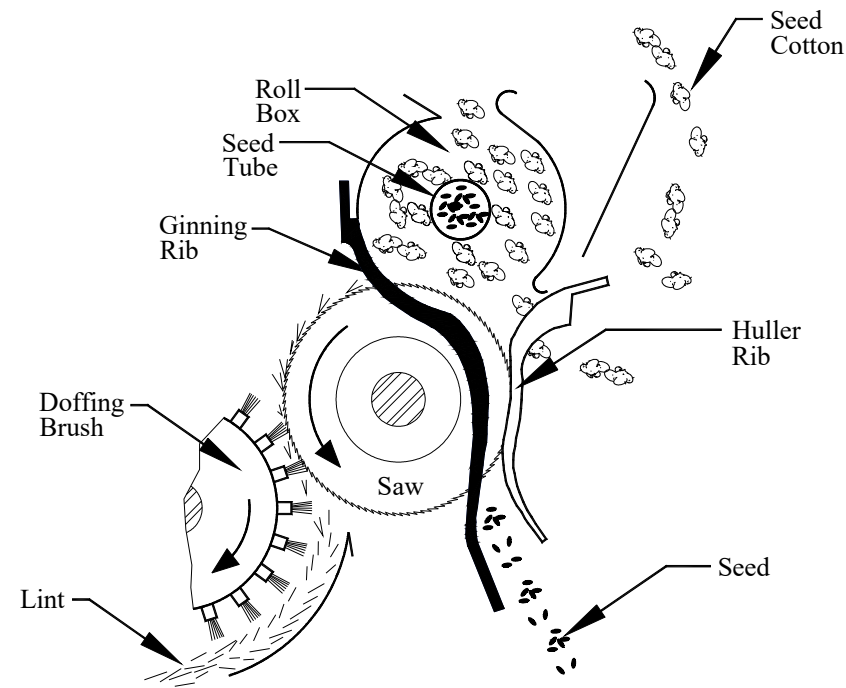

Figure 1. Side view of the saw gin stand used in this experiment. Modern gins do not have huller ribs. tangled fibers and trash. These correlations indicate that it would be prudent to test saw thickness impact on energy using cultivars, production practices, and harvest methods (collectively: growths) representative of different cotton growing regions.

Debate regarding the impact of cotton gin saw thickness on energy consumption and processing rate was based on untested, conflicting theories. To the best of our knowledge, no published work has looked at energy consumption as a function of gin saw thickness. This suggested a controlled experiment was needed to quantify the difference in processing rate and energy consumed per unit of lint processed for different saw thicknesses. This study looked at the impact of having thicker gin saws across the entire width of the gin stand using a 46-saw research gin. We measured processing rate (lint basis), and power and energy consumption, both at idle and under load, of the saw cylinder motor, which also turned the huller front, seed roll seed tube, and doffing brush.

\section{Materials ANd Methods}

The experiment was conducted at the USDA-ARS Southwestern Cotton Ginning Research Laboratory in Las Cruces, New Mexico (SWCGRL) on a Continental Double Eagle with 406 mm (16 in.) diameter saws (Continental Gin Company, Prattville, Ala.) modified for research to a width of 46 saws, or $781 \mathrm{~mm}$ (30.75 in.). The rated ginning capacity for the Continental Double Eagle 96-saw gin stand originally was 0.36 to $0.48 \mathrm{~kg} \mathrm{~s}^{-1}$ [6 to 8 running, or $218 \mathrm{~kg}(480 \mathrm{lb})$, lint bales $\mathrm{h}^{-1}$ ] (Mangialardi Jr. and Anthony, 2005). On a persaw basis, the maximum ginning rate as built was $5.00 \mathrm{~g}$ saw $^{-1} \mathrm{~s}^{-1}$. Modified to 46 saws it was expected to process up to $0.23 \mathrm{~kg} \mathrm{~s}^{-1}$ (approximately 4 lint bales $\mathrm{h}^{-1}$ ).

\section{Determining Processing Rates}

A pre-trial test was conducted to verify the processing rate, and to determine what the maximum processing rate might be at $150 \%$ motor load (possible during our short-duration tests). We did this because commercial gin facilities have been known to put larger motors on their gin stands to increase capacity. For each run, $113 \mathrm{~kg}(250 \mathrm{lb})$ of spindleharvested seed cotton (Delta Pine 1522, Bayer, Leverkusen, Germany) from Las Cruces, New Mexico was pre-cleaned through an inclined cylinder cleaner, a stick machine, and a second inclined cylinder cleaner.

The gin used in this test had an electronic control system that included a ginning rate selector knob to choose the set point and a motor load sensor for feedback. It regulated the speed of the feeder rollers above the gin stand feeder; the feeder rollers controlled the volume rate of seed cotton entering the process. For the first run, the ginning rate selector knob was set to "7", the normal processing rate. For the second run, the ginning rate selector knob was set to " 9 " and the $22.37 \mathrm{~kW}(30 \mathrm{hp})$ gin stand motor percent load limit was set to the maximum, slightly over $150 \%$. Lint turnout, calculated to be $37.16 \%$ for this seed cotton load, was used to estimate the lint processed, and a stopwatch to estimate the run time. These two processing rates, "normal" and "maximum" (max), were the target processing rates for the main 
experiment. They were 0.22 and $0.28 \mathrm{~kg} \mathrm{~s}^{-1}$ (3.71 and 4.63 bales $^{-1}$ ). On a lint rate per saw basis, the target processing rates were 4.88 and $6.08 \mathrm{~g} \mathrm{saw}^{-1} \mathrm{~s}^{-1}$.

The $22.37 \mathrm{~kW}(30 \mathrm{hp})$ motor installed at the initial modification was adequate at the time, but later modifications included adding a circumferentially enclosed conveyor (seed tube) for removal of seeds from the center of the seed roll (fig. 1). The perforated outer tube was powered to avoid stalling the seed roll; this additional load meant that the motor was operating at $119 \%$ of rated power when the processing rate was "normal," and at the maximum processing rate the motor load was about $145 \%$ percent. Motor feeder circuits should be protected by an overload device sized to open at no more than $115 \%$ of the motor nameplate full load amps current rating (NFPA, 2010). For that reason, it was necessary to temporarily increase the setting on the motor overload protection device to run the two-and-a-half to three-minute tests at maximum processing rate. We did not find that the motor temperature rose above safe limits in the short duration of our tests.

\section{Tested SAws}

Two gin saw mandrels were each professionally stacked (assembled with spacers between the saws to obtain precise center-to-center distances) (Precision Gin Works, Lubbock, Tex.) with $406 \mathrm{~mm}$ (16 in.) diameter saws (Phoenix Gin Saws, Hartsville, S.C.) that were robotically trained (McSami Saw Trainer, McCleskey Saw and Machine, Bronwood, Ga.) within $0.127 \mathrm{~mm}$ (0.005 in.) of the plane perpendicular to their axis of rotation (Schramm and and Gill, 2013; U.S. Patent No. 8,590,109). One saw cylinder was a complete set of thin (original equipment thickness) saws [0.9144 $\mathrm{mm}(0.036 \mathrm{in})$.$] , the other consisted of thicker saws$ [1.143 mm (0.045 in.)].

An old rule of thumb was that the gap between ribs is three times the saw thickness, so the space for fiber to pass through on each side is equal to the saw thickness. However, there are other factors, such as seed size, that are more important in the determination of the optimum gap between ribs. Many commercial operators have changed saw thickness but we're not aware that any attempted to modify rib spacing at the same time. For this reason, we did not replace the ribs to account for the thicker saws, so the gap where fiber could pass through was $0.9144 \mathrm{~mm}(0.036 \mathrm{in}$.) for the thin saws, and $0.8001 \mathrm{~mm}(0.0315 \mathrm{in}$.) on each side for the thicker ones. For reference, when the thicker saws were installed our laboratory gin had $20 \%$ less clearance than a commercial gin stand which comes with $1.143 \mathrm{~mm}(0.045 \mathrm{in}$.) saws (Consolidated Cotton Gin Co, Inc., Lubbock, Tex.), as that commercial gin was designed to have $1.003 \mathrm{~mm}$ (0.0395 in.) clearance on each side of the saws.

When a saw cylinder was first installed, it was operated at a reduced processing rate for approximately $2 \mathrm{~h}$ (three bales) to break in the new saws. This was done using a fourth cultivar, which had been spindle-harvested, and that lint was discarded.

\section{EXPERIMENT DESIGN}

Since the most time-consuming variable to change was the thickness of the gin saws, requiring about two days to

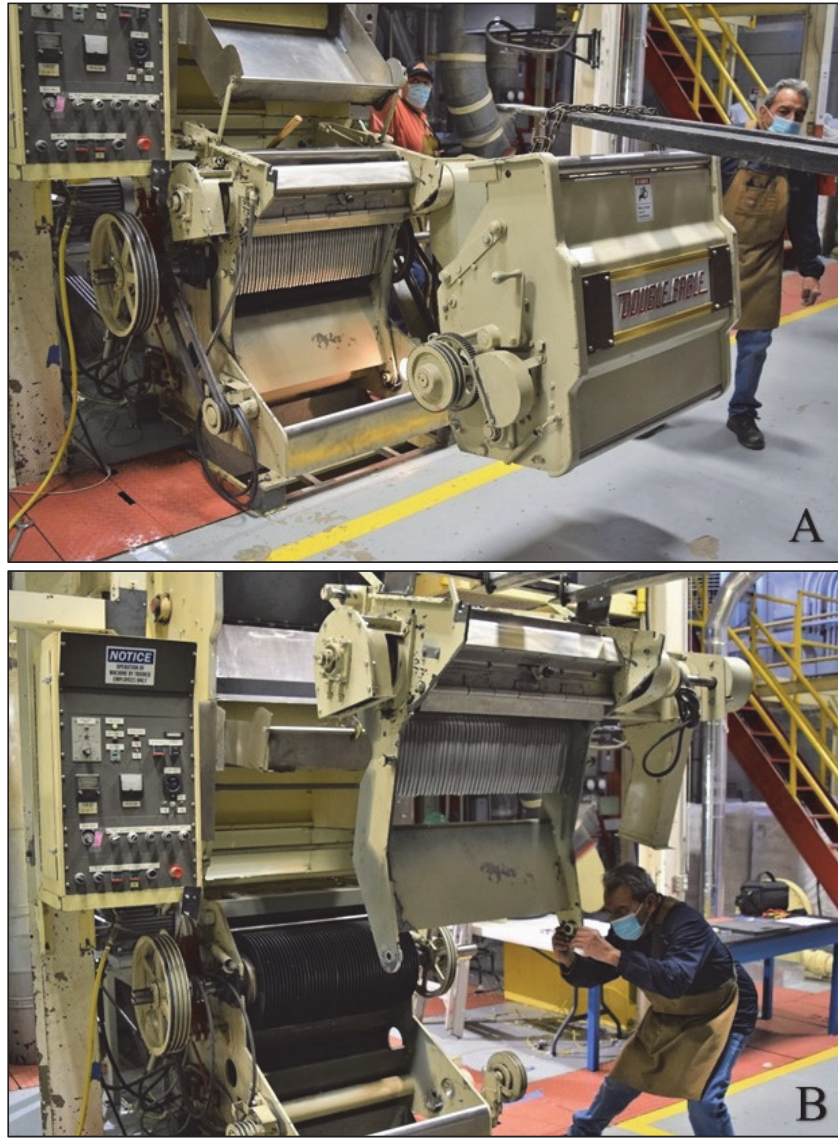

Figure 2. The process of changing a saw cylinder included removing the huller front (A) and the gin breast with its ribs (B).

disassemble and reassemble the gin stand (fig. 2), saw thickness was blocked within replicate. There were five replicates of each saw thickness.

Likewise, to make the best use of resources, we randomized seed cotton growth within each thickness replicate (growth here means the combination of cultivar, production practices, and harvest method unique to each region). The three growths, identified by state of origin, were:

A) a spindle-harvested upland cotton (NexGen 4545 B2XF, Americot, Lubbock, Tex.) from Las Cruces, New Mexico (N. Mex.);

B) a stripper-harvested upland cotton (Deltapine 1549 B2XF, Bayer, Leverkusen, Germany), harvested using a stripper equipped with a field cleaner, from Lubbock, Texas (Tex.);

C) and a spindle-harvested upland cotton (STV 4848, BASF, Ludwigshafen, Germany) from Stoneville, Mississippi (Miss.).

The third variable was lint processing rate. Two target levels, normal $\left(4.88 \mathrm{~g} \mathrm{saw}^{-1} \mathrm{~s}^{-1}\right)$, and maximum $(\max )(6.08 \mathrm{~g}$ saw $\left.^{-1} \mathrm{~s}^{-1}\right)$ were assigned randomly under each cotton growth.

\section{Preparations}

Seed cotton from all three regions was shipped to SWCGRL, pre-cleaned in advance of the test to reduce contamination between growths, and stored in trailers. The two spindle-harvested growths were pre-cleaned using an inclined cylinder cleaner, a stick machine, and a second 
inclined cylinder cleaner. The stripper-harvested growth was pre-cleaned using an inclined cylinder cleaner, two stick machines, and a second inclined cylinder cleaner. These precleaning sequences are considered common practice for each harvest method (Anthony and Mayfield, 1994). The moisture content of each seed cotton growth, from $5.6 \%$ to $8.0 \%$ dry basis, was low enough to not require drying. Pre-cleaning machinery was thoroughly cleaned between each growth to minimize cross-contamination.

\section{Test Procedure}

Once the appropriate saw cylinder was installed, a trailer containing the growth of pre-cleaned seed cotton called for by the experiment design was parked for unloading on the SWCGRL 22,680 kg (50,000 lb) capacity truck scale; reso-

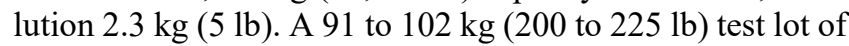
the seed cotton was transferred via suction pipe to the saw gin overflow hopper for temporary storage. That material was then automatically fed to the gin stand during the test run. The gin stand ginning rate selector knob was set for the processing rate, and the overflow feeder was set to supply the required volumetric flow of seed cotton for that processing rate. The seed roll was packed with seed cotton if it was empty. Then the gin machinery was started and the test was run. The preceding steps were then repeated for the second processing rate on the current seed cotton growth. Once both processing rates had been run for the current growth, the seed cotton trailer was removed and a trailer with the next growth was brought into the facility. At the same time, the gin machinery was cleaned to reduce contamination between growths. Tests were then repeated for the second and third growths at both processing rates. Once all three growths had been run, the gin stand was disassembled (fig. 2) and the cylinder with saws of the other thickness was installed. The above was repeated for the next thickness.

To ensure a fair test, ambient temperature and relative humidity were recorded during each run and moisture and trash levels of seed cotton were measured before ginning. These variables were tested for statistical significance in the resulting model. Seed cotton samples (150 g each) collected from the overflow hopper were placed in plastic bags for foreign matter analysis by fractionation (Shepherd, 1972). Additional seed cotton samples (50 g each) were also collected from the overflow hopper and placed in air-tight containers for moisture content determination by oven method (Funk et al., 2018).

\section{QUANTIFYING ENERGY}

During each run, total run time measured by a stopwatch and power factor, power, voltage and current measured by a hand-held meter (Extech 380976, FLIR Systems, Inc., Wilsonville, Ore.) were manually recorded. The current flow to the gin saw motor was quantified using three split-core 4 to 20 milliamp current transmitters (H-921 Hawkeye, Veris, Portland, Ore.) set to $120 \mathrm{~A}$ and installed on each leg of the three-phase $220 \mathrm{VAC} 22.37 \mathrm{~kW}(30 \mathrm{hp})$ motor. The 4-20 milliamp signals were converted to $0-10 \mathrm{~V}$ values by $500 \mathrm{k} \Omega$ precision resistors. These values were recorded every second $(1 \mathrm{~Hz})$ using a data logger (Agilent 34972A, Keysight, Santa Clara, Calif.) through 40 channel interface cards (34907A, Keysight). At the same time, power factor and other energy variables were recorded every $30 \mathrm{~s}$ on a separate logging system (T-VER-E50B2, Veris, Portland, Ore. and HOBO UX120-017M, Onset Computer Corp., Bourne, Mass.) that used 150-A split core current transformers (ACTL-0750-150, Continental Control Systems, LLC, Longmont, Colo.). Data was transferred using USB portable thumb drives (Agilent 34972A) or directly uploaded (HOBO UX120-017M) and saved in spreadsheets for processing and later analysis.

The measured current value was used to calculate the power drawn by the three-phase motor every second during each test, as well as during idle. Power was calculated using these, and the voltage and power factor recorded by the Veris/Onset system.

The lint produced by each run was kept separate and later weighed on our bale scale [Model 7332F, Hobart, Troy, Ohio, resolution $0.23 \mathrm{~kg}(0.5 \mathrm{lb})]$. The processing rate was calculated by dividing the lint mass processed by the time required to process it. The power used by the gin stand motor, less idle power, was integrated every second over the test period and divided by the lint mass to calculate the specific energy used (eq. 1):

$$
\begin{aligned}
& \text { Net Energy }\left(\mathrm{W}-\mathrm{h} \mathrm{kg}^{-1}\right)= \\
& \frac{\int[\operatorname{Gin} \text { Power }(W)-\text { Idle Power }(W)]}{\text { Lint Mass }(\mathrm{kg})}
\end{aligned}
$$

Between growths the seed roll was emptied. This meant that there was a small systemic error in the processing rate calculation because of the time required to build up the seed roll after switching from one growth to the next. That was accounted for by keeping track of whether a particular run was the first, needing time to build up the seed roll, or the second, starting with a full seed roll. Typically, the time to build up the seed roll (the delay before seed began to fall onto the seed conveyor) averaged 20 seconds. This 20 s period of seed roll build up was included in the analysis for two reasons: it was not feasible to separate lint ginned during seed roll build up from the total, and including it did not affect results in a statistically significant way.

\section{Statistical Analysis}

Statistical analyses were conducted using the Fit Model specification in the JMP statistical package (Version 13.2, SAS Institute Inc., Cary, N.C.). The null hypothesis was that there is no difference in energy consumption between gin saws 0.9144 and $1.143 \mathrm{~mm}$ thick. Uncontrolled variables that were also explored included processing rate, ambient temperature and relative humidity, date, time of day, test duration, and lot weights. The response (dependent) variable net ginning energy per lint mass (W-h kg-1) was modeled with controlled (independent) variables saw thickness, cotton growth, their interaction, and the continuous variable processing rate (covariate). Uncontrolled (covariate) variables ambient temperature and relative humidity, test duration, lint turnout, and presence or absence of a seed roll at the start of each test run were included in the initial model. Seed cotton moisture content was not included because this 
metric was confounded with growth. A backwards regression approach was used to eliminate variables that had little influence on the model.

\section{RESULTS AND DISCUSSION \\ DATA QuALITY}

The three systems used to measure volts, amps, and power factor for computing watt-hours were compared. The primary system used to record motor current was the Keysight 34972A; power estimates calculated using this system were within $5 \%$ of the values recorded by the Veris/Onset data logging system. Voltage, current, and power factor readings from the two logging systems agreed within $4 \%$ to what had been manually recorded from the FLIR-Extech hand-held meter. Test duration, also a key input variable, was calculated by summing the count (each second) when values for motor power based on Keysight 34972A data were $2 \mathrm{~kW}$ above the power at idle. The test duration in seconds determined this way agreed within $4 \%$ to the test duration recorded by stopwatch and by the value manually recorded from the seconds counter on the gin stand control system.

\section{Seed Cotton Moisture Content}

Seed cotton moisture content is a function of the moisture content of seed, which is relatively stable, and lint, which changes rapidly; they have different equilibrium moisture contents in the same conditions. Both precleaning and ginning are sensitive to lint moisture content, so cotton gins often use dryers during the pre-cleaning process (Childers and Baker, 1978). Ambient relative humidity can also affect lint moisture content, as it might have done in this test. Table 1 presents seed cotton moisture content information from samples taken at the time of each test run. In equilibrium, seed cotton at $5.6 \%, 6.5 \%$, and $8.0 \%$ moisture content dry basis (N. Mex., Tex., and Miss., respectively) would correspond to lint moisture contents of $4.4 \%, 5.5 \%$, and $6.3 \%$ dry basis. The ideal lint moisture content for ginning is $6.4 \%$ to $7.5 \%$ dry basis (Hughs et al., 1994). Our tests were run when fiber moisture was below the ideal range, which, according to Hardin IV et al. (2018), may have affected processing rate. However, the values were within the range found in the context of commercial cotton ginning and were representative of what might be found in each of their respective regions, depending on weather at the time of harvest and ginning. After shipment to Las Cruces the seed cotton was stored in uncovered trailers with wire mesh sides for from 6 to 12 weeks. We think that seed cotton moisture content differences between regions persisted despite low relative humidity in Las Cruces because most of the moisture was in the seed, and seed moisture changes slowly relative to lint moisture content.

$\begin{gathered}\text { Table 1. Seed cotton moisture content, dry basis, at the time of each } \\
\text { test; average, maximum, minimum, and standard deviation. }\end{gathered}$
\begin{tabular}{ccccc} 
Avg. & Max. & Min. & StDev \\
Growth & $(\%)$ & $(\%)$ & $(\%)$ & $(\%)$ \\
\hline A (New Mexico) & 5.6 & 5.8 & 5.2 & 0.19 \\
B (Texas) & 6.5 & 7.0 & 5.9 & 0.24 \\
C (Mississippi) & 8.0 & 9.0 & 5.5 & 0.83 \\
\hline
\end{tabular}

\section{Seed Cotton Processing Rate}

Using the gin stand ginning rate selector knob to control processing rate did not result in target processing rates being met, but it did result in two distinct rates for each growth. On a lint rate per saw basis, processing rates averaged 4.51 for "normal" (instead of 4.88) and 5.40 for "max" (instead of 6.08) $\mathrm{g} \mathrm{saw}^{-1} \mathrm{~s}^{-1}$ (table 2). Processing rate was not intended to differ with saw thickness; the ginning rate selector knob was set to the same target value independent of saw thickness. However, since the control system was designed to maintain a constant motor load there was a difference in processing rate (maintaining a constant motor load and varying the feed rate is common practice in commercial ginning). The cylinder with thicker saws averaged about $90 \%$ of that of the cylinder with thinner saws, 4.692 and $5.213 \mathrm{~g} \mathrm{saw}^{-1} \mathrm{~s}^{-1}$, respectively. It was not a surprise to observe that processing rate also was sensitive to the cotton growth being ginned. The cultivar grown in New Mexico had a higher processing rate than the spindle-harvested and stripper-harvested cultivars from Mississippi and Texas for a given ginning rate selector knob setting. This could be due to some combination of fiber attachment force, moisture and trash content, and seed size relative to fiber mass (all having genetic and environmental influences). An earlier study found significant differences between cultivars, all else being equal (Boykin, 2007).

\section{GINNING ENERGY}

The response (dependent) variable net ginning energy per lint mass (W-h kg-1) was plotted on the controlled (independent) variable processing rate $\left(\mathrm{g} \mathrm{saw}^{-1} \mathrm{~s}^{-1}\right)$ for each combination of saw thickness and seed cotton growth (fig. 3). The thicker saws appeared to require more energy, as did ginning at a higher processing rate. Energy requirements differed for each growth. Curves associated with each data set assumed zero energy at zero processing rate.

\section{GiNNING ENERgy Model}

A backwards regression approach was used to eliminate variables that had little influence on the model, retaining variables with a P-Value less than 0.25 , until an Analysis of Covariance (ANCOVA) model with seven degrees of freedom and with four significant variables and one significant interaction resulted. The significant terms were (in rank order): cotton growth; processing rate; saw thickness; interaction between saw thickness and cotton growth; and relative humidity at the time of the test. The influence of the last two terms was slight, but both were statistically significant with a P-Value less than 0.05 (table 3). Presence and absence of a seed roll at the start of a test run, discussed above, did not have a significant effect on processing rate so this variable was removed from the model. The variables remaining in the

Table 2. Processing rate in grams per saw per second $\left(\mathrm{g} \mathrm{saw}^{-1} \mathrm{~s}^{-1}\right)$ for each growth.

\begin{tabular}{lccc}
\hline & \multicolumn{3}{c}{ Per secossing Rate $\left(\mathrm{g} \mathrm{saw}^{-1} \mathrm{~s}^{-1}\right)$} \\
\cline { 2 - 4 } \multicolumn{1}{c}{ Growth } & Normal Rate & Maximum Rate & Average \\
\hline Mississippi & 4.47 & 5.15 & 4.81 \\
New Mexico & 4.68 & 5.77 & 5.22 \\
Texas & 4.38 & 5.27 & 4.82 \\
\hline Average & 4.51 & 5.40 & \\
\hline
\end{tabular}




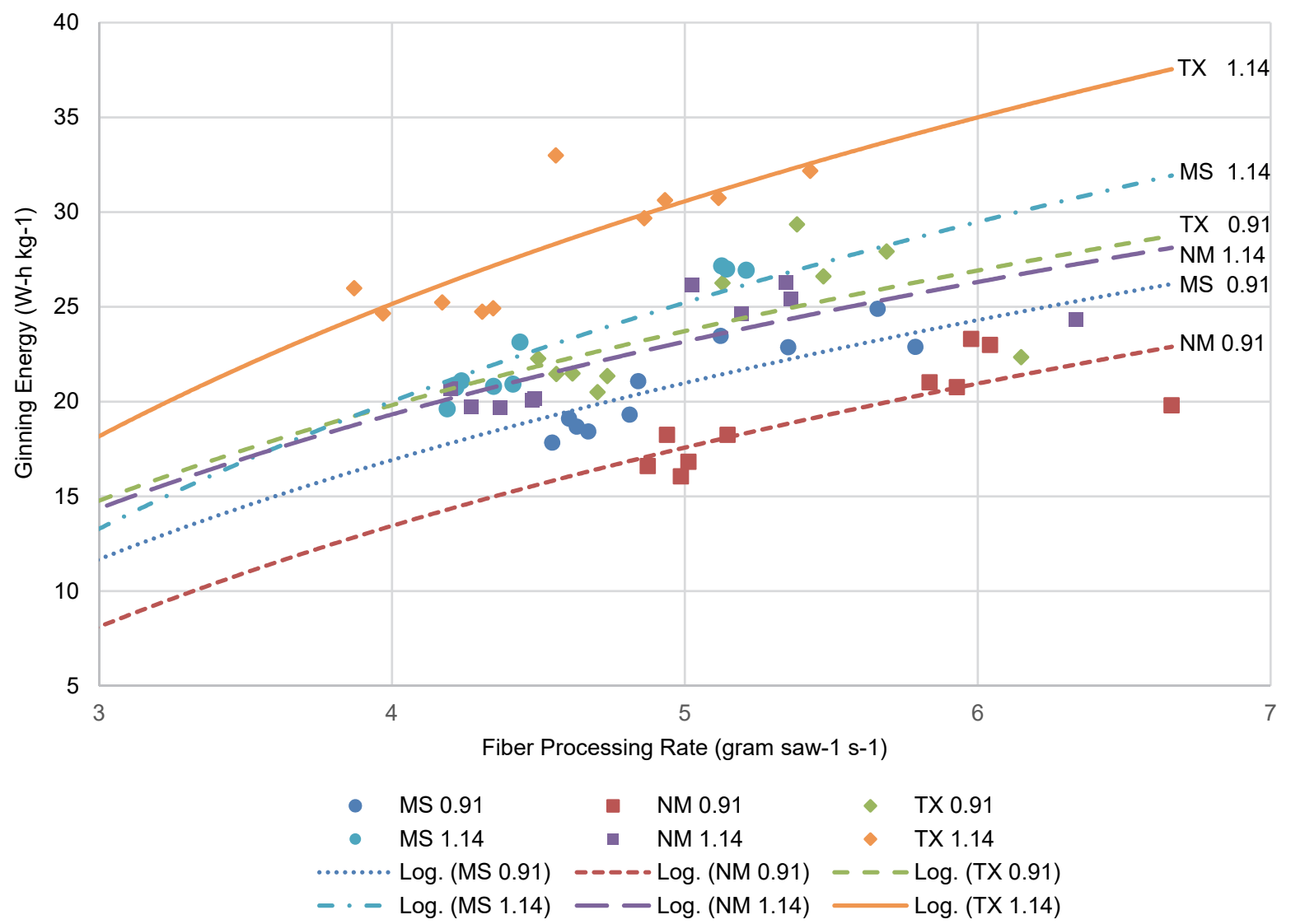

Figure 3. Net ginning energy $\left(\mathrm{W}-\mathrm{h} \mathrm{kg}^{-1}\right)$ on fiber processing rate for each combination of growth and saw thickness.

Table 3. Effects tests from the reduced statistical model.

\begin{tabular}{lcccr}
\hline \multicolumn{1}{c}{ Variable } & $\begin{array}{c}\text { Degrees of } \\
\text { Freedom }\end{array}$ & $\begin{array}{c}\text { Sum of } \\
\text { Squares }\end{array}$ & F Ratio & $\begin{array}{r}\text { P-Value } \\
(\text { Prob }>\text { F) }\end{array}$ \\
\hline Cotton growth & 2 & 377.709 & 58.854 & $<0.0001^{*}$ \\
Processing rate & 1 & 289.759 & 90.2995 & $<0.0001^{*}$ \\
Saw thickness & 1 & 273.294 & 85.1685 & $<0.0001^{*}$ \\
Saw thickness*cotton & 2 & 28.052 & 4.371 & $0.0178^{*}$ \\
RH & 1 & 13.656 & 4.2558 & $0.0443^{*}$ \\
\hline [a] P-Valo
\end{tabular}

[a] P-Values followed by an * indicates significance at the 0.05 level.

model explained $82 \%$ of the variability in the response (model $\mathrm{R}^{2}$ was 0.824474 ). The least squares means (modelbased mean values that account for covariates, interactions, and missing data) for net ginning energy for all three growths are presented for both saw thicknesses in figure 4.

Comparing the averages from the experimental data one may conclude that the thicker gin saws require more energy than the thinner ones. The LS Means of the net energy

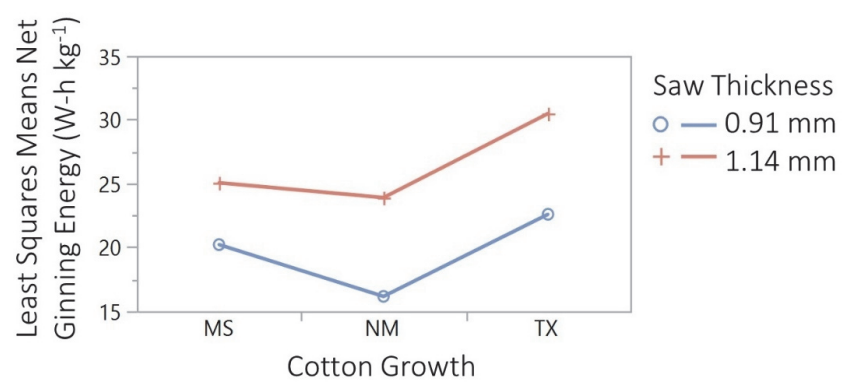

Figure 4. Least Squares Means Plot showing net ginning energy $\left(\mathrm{W}-\mathrm{h} \mathrm{kg}^{-1}\right)$ as a function of saw thickness and cotton growths. indicate that the thicker $(1.143 \mathrm{~mm})$ gin saws used 26.48 W-h kg-1 compared to $19.65 \mathrm{~W}-\mathrm{h} \mathrm{kg} \mathrm{kg}^{-1}$ for the $0.914 \mathrm{~mm}$ saws - nearly $35 \%$ more energy to process the same amount of lint cotton (table 4).

\section{RIB GAP EFFECT}

The gap between ribs was not adjusted to accommodate the thicker saws; the gin stand used for this experiment came from the manufacturer with a rib gap of $3.048 \mathrm{~mm}$ (0.120 in.), resulting in $1.067 \mathrm{~mm}$ (0.042 in.) clearance on each side with original saws. Operating with thicker saws resulted in clearance on each side being reduced to $0.9526 \mathrm{~mm}$ (0.0375 in.), a decrease of $11 \%$. Experimentally this may be viewed as confounding, but it is representative of normal practice in industry, where gin saw thickness, if changed, is often changed while ribs are not. Saws flex during ginning, so the gap was not constant, but this may in part explain the $35 \%$ increase in energy use. The smaller clearance between saws and ribs may also explain why the processing rate decreased by $10 \%$ with the thicker saws, as the feed control system responded to motor load increasing with additional friction. The only way to answer this question will be to conduct an experiment varying the rib gap instead of the saw thickness.

\section{ECONOMIC IMPACT}

Energy audits from 2009 to 2011 (Funk et al., 2013) indicated that $18.5 \%$ of electrical energy used by a gin was used for ginning (Beltwide average). Data from the most recent 
Table 4. Net ginning energy by growths and saw thicknesses for the experimental data (experiment means) and the statistical model (least squares means - considered to better reflect reality by accounting for covariates, interactions, and missing data).

\begin{tabular}{|c|c|c|c|c|c|c|}
\hline \multirow[b]{4}{*}{ Growth } & \multicolumn{6}{|c|}{ Net Ginning Energy W-h kg ${ }^{-1}$} \\
\hline & \multicolumn{3}{|c|}{ Experiment Means } & \multicolumn{3}{|c|}{ Least Squares Means from Model } \\
\hline & \multicolumn{2}{|c|}{ Saw Thickness } & \multirow[b]{2}{*}{ Average } & \multicolumn{2}{|c|}{ Saw Thickness } & \multirow[b]{2}{*}{ Average } \\
\hline & $0.914 \mathrm{~mm}$ & $1.143 \mathrm{~mm}$ & & $0.914 \mathrm{~mm}$ & $1.143 \mathrm{~mm}$ & \\
\hline MS & 20.85 & 23.05 & 21.95 & 20.21 & 25.06 & 22.64 \\
\hline NM & 19.38 & 22.71 & 21.04 & 16.16 & 23.90 & 20.03 \\
\hline TX & 23.96 & 28.18 & 26.07 & 22.59 & 30.48 & 26.53 \\
\hline Average & 21.39 & 24.65 & & 19.65 & 26.48 & \\
\hline
\end{tabular}

Cost of Ginning Survey (Holt et al., 2021) indicated that electricity costs per bale were $\$ 4.18$ (Beltwide average). Increasing ginning energy requirements by $35 \%$ would increase processing costs $\$ 0.27$ per bale. Repairs and Bagging and Ties are constant per bale independent of processing rate, but labor and energy costs increase per unit processed as processing rate decreases. Using Beltwide averages from the cost of ginning survey $(\$ 9.69, \$ 4.18$, and $\$ 1.12$ for labor, electricity, and fuel, respectively), reducing processing rate to $90 \%$ could add $\$ 1.67$ per bale to ginning costs. Combining energy use increase with decreased processing rate, thicker saws could add $\$ 1.94$ per bale to the cost of ginning.

\section{Fiber QUALITY}

Lint and seed samples were collected for coproduct value analyses. That data will be published elsewhere once it has been analyzed.

\section{CONCLUSiOnS}

Tests were conducted to compare the difference in ginning performance between two gin saw cylinders stacked with saws of different thicknesses $(0.9144$ and $1.143 \mathrm{~mm})$ using cottons grown in New Mexico, Texas, and Mississippi. The thicker saws averaged $90 \%$ the processing rate of the thinner saws. Net ginning energy of the thicker gin saws was $35 \%$ higher than net energy of the thinner saws. These results were consistent for all three growths (cultivars/regions). For this test, the gap between gin stand saws and ribs was not adjustable and was thus $12.5 \%$ less than the gap for the thicker saws, which may have had an influence on the results. However, commercial facilities do not usually change ribs when changing to thicker saws, so the test represented common practice. In this test, greater saw thickness decreased processing rate and increased energy consumption. Therefore, while thicker saws should continue to be used at the saw cylinder ends where seed roll densities are high, at this time converting thinner saws to thicker saws across the entire saw cylinder appears to offer no advantage with regard to processing rate or energy use.

\section{ACKNOWLEDGEMENTS}

The authors acknowledge the contribution of lab personnel Kirk Zivkovich, Cassy Salvatti, Branyan Sanxter, Tye Lightfoot, Ernest Herrera, Juan Gomez, Arnold Gomez, Russel Gardner, and Paul Delgado; they stayed healthy and accomplished much under pandemic guidelines.

\section{REFERENCES}

Anthony, W. S., \& Mayfield, W. D. (1994). Cotton ginners handbook. Washington, DC: U.S. Government Printing Office.

Boykin, J. C. (2007). Cultivar differences in gin stand energy utilization. Trans. ASABE, 50(3), 733-743. https://doi.org/10.13031/2013.23128

Childers, R. E., \& Baker, R. V. (1978). Effect of moisture conditioning on ginning performance and fiber quality of High Plains cotton. Trans. ASAE, 21(2), 379-384. https://doi.org/10.13031/2013.35308

Funk, P. A., \& Hardin IV, R. G. (2017). Energy utilization and conservation in cotton gins. J. Cotton Sci., 21, 156-166.

Funk, P. A., Hardin IV, R. G., Hughs, S. E., \& Boykin, J. C. (2013). Changes in cotton gin energy consumption apportioned by ten functions. J. Cotton Sci., 17, 174-183.

Funk, P. A., Terrazas, A. A., Yeater, K. M., Hardin IV, R. G., Armijo, C. B., Whitelock, D. P.,... Delhom, C. D. (2018). Procedures for moisture analytical tests used in cotton ginning research. Trans. ASABE, 61(6), 1985-1995. https://doi.org/10.13031/trans.12980

Funk, P., \& Hardin, R. (2012). Cotton gin electrical energy use trends and 2009 audit results. Appl. Eng. Agric., 28(4), 503-510. https://doi.org/10.13031/2013.42078

Hardin IV, R. G., \& Funk, P. A. (2012). Electricity use patterns in cotton gins. Appl. Eng. Agric., 28(6), 841-849. https://doi.org/10.13031/2013.42471

Hardin IV, R. G., Barnes, E., Valco, T., Martin, V., \& Clapp, D. (2018). Effects of gin machinery on cotton quality. J. Cotton Sci., 22(1), 36-46.

Holt, G. A., Ashley, H., Findley, D. S., Green, J. K., Isom, R. A., Price, T. L.,... Wanjura, J. D. (2021). The cost of ginning cotton - 2019 survey results. Proc. Beltwide Cotton Conf. (pp. 1-7). Cordova, TN: National Cotton Council.

Hughs, S. E., Mangialardi Jr., G. J., \& Jackson, S. G. (1994). Moisture controls. In Cotton Ginners Handbook; USDA-ARS, Agricultural Handbook No. 503 (pp. 58-68). Washington, DC: USDA.

Mangialardi Jr., G. J., \& Anthony, W. S. (2005). Cotton gin saw developments. Cordova, TN: National Cotton Ginners Assoc.

NFPA. (2010). NEC Article 430. In National electrical code. Quincy, MA: National Fire Protection Association.

Schramm, T. W., \& Gill, K. K. (2013). Apparatus and methods for automatically training saw blades on a saw mandrel. U.S. Patent No. 8,590,109.

Shepherd, J. V. (1972). Standard procedures for foreign matter and moisture analytical tests used in cotton ginning research. Agricultural Handbook No. 442. Washington, DC: U.S. Government Printing Office, Stock No. 0100-1509. 